\title{
Flexible programmes in higher professional education: expert validation of a flexible educational model
}

Citation for published version (APA):

Schellekens, A., Paas, F., Verbraeck, A., \& van Merrienboer, J. J. G. (2010). Flexible programmes in higher professional education: expert validation of a flexible educational model. Innovations in Education and Teaching International, 47(3), 283-294. https://doi.org/10.1080/14703297.2010.498179

Document status and date:

Published: 01/01/2010

DOI:

10.1080/14703297.2010.498179

Document Version:

Publisher's PDF, also known as Version of record

\section{Document license:}

Taverne

Please check the document version of this publication:

- A submitted manuscript is the version of the article upon submission and before peer-review. There can be important differences between the submitted version and the official published version of record.

People interested in the research are advised to contact the author for the final version of the publication, or visit the DOI to the publisher's website.

- The final author version and the galley proof are versions of the publication after peer review.

- The final published version features the final layout of the paper including the volume, issue and page numbers.

Link to publication

\footnotetext{
General rights rights.

- You may freely distribute the URL identifying the publication in the public portal. please follow below link for the End User Agreement:

www.umlib.nl/taverne-license

Take down policy

If you believe that this document breaches copyright please contact us at:

repository@maastrichtuniversity.nl

providing details and we will investigate your claim.
}

Copyright and moral rights for the publications made accessible in the public portal are retained by the authors and/or other copyright owners and it is a condition of accessing publications that users recognise and abide by the legal requirements associated with these

- Users may download and print one copy of any publication from the public portal for the purpose of private study or research.

- You may not further distribute the material or use it for any profit-making activity or commercial gain

If the publication is distributed under the terms of Article $25 \mathrm{fa}$ of the Dutch Copyright Act, indicated by the "Taverne" license above, 


\section{Flexible programmes in higher professional education: expert validation of a flexible educational model}

Ad Schellekens, Fred Paas, Alexander Verbraeck \& Jeroen J.G. van Merriënboer

To cite this article: Ad Schellekens, Fred Paas , Alexander Verbraeck \& Jeroen J.G. van Merriënboer (2010) Flexible programmes in higher professional education: expert validation of a flexible educational model, Innovations in Education and Teaching International, 47:3, 283-294, DOI: $10.1080 / 14703297.2010 .498179$

To link to this article: https://doi.org/10.1080/14703297.2010.498179

曲 Published online: 12 Aug 2010.

Submit your article to this journal 준

III Article views: 311

Q View related articles $\sqsubset$

Citing articles: 2 View citing articles $\sqsubset \pi$ 


\title{
Flexible programmes in higher professional education: expert validation of a flexible educational model
}

\author{
Ad Schellekens $^{\mathrm{a} *}$, Fred Paas ${ }^{\mathrm{b}}$, Alexander Verbraeck ${ }^{\mathrm{c}}$ and Jeroen J.G. van \\ Merriënboer ${ }^{\mathrm{a}, \mathrm{d}}$ \\ ${ }^{a}$ Centre for Learning Sciences and Technologies (CELSTEC), Open Universiteit Nederland, \\ Heerlen, The Netherlands; ${ }^{b}$ Institute of Psychology, Erasmus University Rotterdam, \\ Rotterdam, The Netherlands; ${ }^{c}$ Faculty of Technology, Policy and Management, Delft \\ University of Technology, Delft, The Netherlands; ${ }^{a}$ Department of Educational Development \\ and Research, Maastricht University, Maastricht, The Netherlands
}

\begin{abstract}
In a preceding case study, a process-focused demand-driven approach for organising flexible educational programmes in higher professional education (HPE) was developed. Operations management and instructional design contributed to designing a flexible educational model by means of discrete-event simulation. Educational experts validated the model and evaluated its practical value and possible impact on education. It was concluded that the flexible educational model offers a valid representation of HPE institutes in The Netherlands and can contribute to the flexibility and innovation of educational programmes.
\end{abstract}

Keywords: educational model; organisation of education; operational flexibility; simulation; expert validation; professional education; higher education

\section{Introduction}

In the perspective of lifelong learning there is an increasing need for customised education and training. Flexible programmes meet the individual needs of students for learning on demand (Markkula, Van der Perre, \& Claeys, 2000). In a survey study, Schellekens, Paas, and Van Merriënboer (2003) found that programmes in higher professional education (HPE) in The Netherlands have a typical operational format and that changing this format is necessary to increase flexibility, for instance, to customise programmes to the students' needs. Operational flexibility was defined as the degree of flexibility according to a set of operational characteristics of educational programmes.

Schellekens, Paas, Verbraeck, and Van Merriënboer (2009) describe a case study in a faculty of economics of a large HPE institute in The Netherlands. The faculty offered six initial training programmes for a population of more than 2000 full-time and part-time students. In that study a flexible operational approach for organising educational programmes was developed using concepts and principles from operations management and instructional design. The programmes were redesigned according to a competence-based educational approach. Real data were used to design

\footnotetext{
*Corresponding author. Email: ad@schellekens.net
} 
a flexible educational model by means of discrete-event simulation. The model was positively validated by programme managers of the institute.

In the present study, the flexible educational model was considered from the perspective of innovations in Dutch HPE. In an introductory section, the common and the flexible educational models are described. The concept of flexibility is reconsidered in a broader perspective. In the research section, the method, results and conclusions of an expert validation of the flexible educational model are described and discussed.

\section{The common educational model}

In the past decades, several developments influenced the common educational model in Dutch HPE. Concentration and merging brought larger educational institutes. Modularisation (i.e. structuring curricula into modules) has standardised and systematised educational programmes, which lacked integration. A thematic approach restored their coherence and changed the teaching and learning activities. As a result, educational programmes got typical operational characteristics.

\section{Operational characteristics}

In The Netherlands, HPE students normally participate in one specific educational programme, which formally requires four years of study. A study year starts in September and lasts until the end of June. Each year comprises 42 study weeks and is usually segmented in four study periods. A study week nominally counts as 40 hours of study, equaling 1 study credit (sc). A complete four-year programme consists of $168 \mathrm{sc}$.

Educational programmes are organised in classes at an educational institute. In a full-time programme (Figure 1) students usually spend a full year outside the institute in internships. In a normal study period, students participate in a programme block with several modules (e.g., courses) for a total of about 400 study hours. A 50-hour course, for instance, weekly requires about five study hours, of which one or two hours are spent in classes, and the remaining hours in small-group activities at the institute and individual study at home. Programme blocks usually have eight weeks with weekly repeated lessons, and two weeks for preparing and doing tests.

From an institute's perspective, programmes are organised for year cohorts of students. Thus, in any study year all the programme components are offered to different student cohorts. Students participate in programme-specific year-groups. Normally, full-time students are at the institute during the day, and part-time students

\begin{tabular}{r|c:c:c:c|} 
Period & 1 & 2 & 3 & 4 \\
\hline Year 1 & Block 1.1 & Block 1.2 & Block 1.3 & Block 1.4 \\
\hline 2 & Block 2.1 & Block 2.2 & Block 2.3 & Block 2.4 \\
3 & Block 3.1 & Block 3.2 & Block 3.3 & Block 3.4 \\
4 & Block 4.1 & Block 4.2 & Block 4.3 & Block 4.4 \\
\hline
\end{tabular}

Figure 1. Diagram of the programme structure for a student. Blocks 3.1, 3.2, 4.3, and 4.4 (dark shading) concern internships (apprenticeships). 
in the evening. Periodic scheduling is an efficient approach to organising student groups, teaching staff and accommodation for a range of programmes. Owing to internships, accommodation is required for just three instead of four student cohorts. Modularisation has increased efficiency by sharing a substantial amount of programme modules in related programmes. However, a practice of cohort- and programme-based student grouping restricts programme flexibility and is typical for the common educational model.

\section{The flexible education model}

\section{Main principles}

In the flexible educational model the supply-oriented approach and product-focused strategy of the common educational model were replaced by a demand-oriented approach and a process-focused strategy, according to operations management concepts (Krajewski \& Ritzman, 1996). The curriculum was restructured in line with the Four-Component Instructional Design (4C/ID) model (Van Merriënboer, 1997), applying a competence-based educational approach.

\section{Demand-oriented approach}

In the common educational model, programmes are considered as a standard treatment for all students. Students differ, for instance, in capabilities, prior knowledge, and interests. Changing circumstances may urge them to adapt the balance of time between study and work. In the flexible educational model students have their own customised programmes stored in a personal dossier. The actual demands of the students determine the planning of the educational institute.

\section{Process-focused strategy}

In the common educational model, programmes are organised by a product-focused strategy based on the professional profiles of students. Modularised curricula allow a process-focused strategy, in which programmes are no longer organised in a standard operational pattern with programme-based year-groups, fixed study periods and study years. Educational support activities (e.g., courses) can start at any moment in a year and vary in study time, duration, and educational approach. Accordingly, students can plan their own activities using their available study time in an optimal way and take full advantage of personal capacities, prior knowledge and experience, without being obstructed or pushed by a standard programme. As a result, the programme of each individual student has a specific operational pattern, which is illustrated in Figure 2.

\section{Competence-based education}

Consistent with the 4C/ID model (Van Merriënboer, 1997), task-directed activities (projects) are considered as core activities of a programme, supported by knowledge- and skill-directed study activities (courses). In the flexible model, projects consist of authentic work activities in realistic settings. Part-time students participate in a variable number of projects, aiming at competence development. Tasks are adapted to their educational needs, and each project is intensively coached by a 


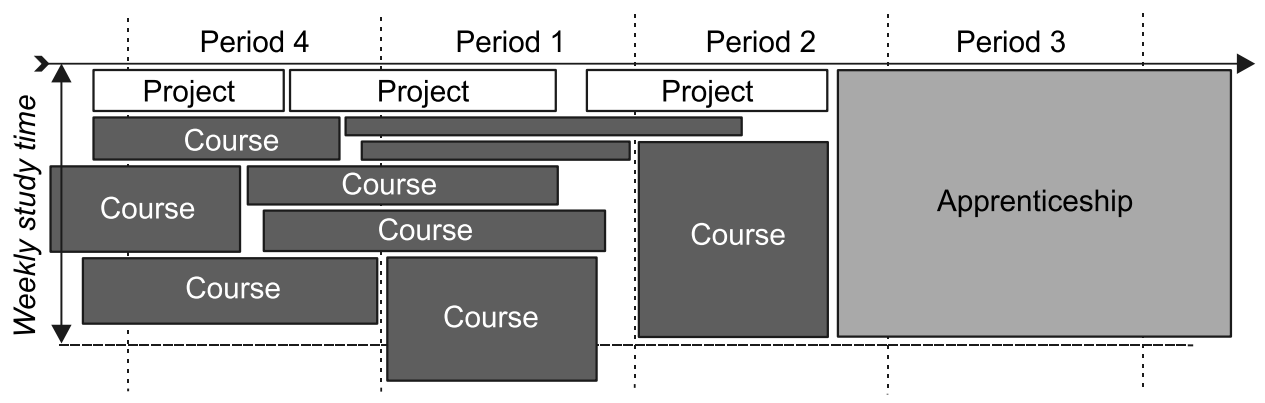

Figure 2. Diagram of a part of the programme of an individual student, according to the simulation of the integral flexible model of the second case study. This diagram illustrates the operational pattern of a programme, which is different for each student.

specific member of the teaching staff. Courses are organised on demand, meeting efficiency criteria. Duration and educational setting may vary as needed, as in normal classes, large-group lectures and walk-in practicals. For an adequate buildup of the study programmes, courses are part of a well-structured curriculum. Participation in projects supported by actually relevant courses constitutes a competence-based approach of programmes, which are customised to the specific needs of individual students.

\section{Operational characteristics}

Teachers coach projects, teach courses, or do both, with additional tasks in acquiring and preparing projects or developing courses. Coaching staff is organised in relevant professional fields and profiles. Teaching staff is organised along disciplinary lines. Staff units operate as autonomous teams planning their own activities in order to meet the actual educational needs of the students. Students put their planning preferences in personal dossiers, which are frequently analysed in order to enable staff units to decide which activities must be started. Staff and students can optimise their planning according to their own priorities and conditions. Staff members can vary the tasks within their teams. Students can adapt their time for study and work. Owing to the process-focused strategy, capable students can complete their programmes faster than others.

The process-focused strategy changes education into a continuous enterprise. The use of accommodation and facilities is no longer centrally scheduled. Students and teachers largely dispose their own accommodation and facilities. Information and communication technology (ICT) extends teaching and learning beyond opening hours. A reliable technical infrastructure is essential for flexible planning and coordination, and to support the diverging activities of students and teachers in several ways.

In the programmes, projects and courses are complementary. Assessment primarily focuses on competence development and certification of students. In projects, successive coaches judge the competence development and qualities of individual students. In courses, students are tested and credited for supporting knowledge and mastery of skills.

Programmes, projects and courses are no longer constrained by fixed study years, study periods and fixed weekly study hours. The flexible approach enables 
one flexible programme-variant, instead of dedicated standard programmes for fulltime and part-time students. Students can start and interrupt their programmes at any moment in a study year without substantial loss of time. They are grouped as needed, for projects in vertical groups, and for courses in horizontal groups, instead of in permanent cohort- and programme-based groups. Institutes can offer a large variety of programmes, instead of a few predefined programmes, without limiting thresholds of student numbers. Educational services can be effectively offered the whole year around, exceeding the 42 weeks of a conventional study year.

\section{Educational opportunities}

The new operational features enable a true paradigm shift in education, which is facilitated by levelling out the persistent thresholds of the traditional operational format in educational programmes. Predefined 'educational' projects and apprenticeships can be replaced by real work in projects and jobs. The flexible educational model allows prioritising competence development in realistic task settings. Task-directed activities can be used to build a core programme for the students, which can be customised to their individual needs. The increased operational flexibility of the model creates a new mode of 'dual education'. Real projects or work in a job setting can be supported in a flexible way by knowledge- and skill-directed activities, which can be customised to the actual educational and personal needs of the students. Student and teacher roles can be varied according to these new educational settings. Educational institutes may become true service institutes with a varied package of services in an open educational structure, where competition for quality and excellence is encouraged by motivating task settings, and by intensive coaching opportunities.

\section{Implementation}

By designing the flexible educational model according to the characteristics for flexible programmes, the model, by definition, leads to operational features favouring flexibility, and enables the educational features mentioned earlier. However, before the flexible educational model can actually be implemented in HPE institutes, the aims for applying the model must be clarified and decided upon. Increasing the flexibility of educational programmes can be considered as an intermediate goal, which contributes to the solution of urgent actual organisational problems of students, teachers and institutes. But the flexible educational model can also be applied to support and anticipate future developments in the professional area and in society, in order to enable and promote necessary innovations in education. An international study on flexibility in vocational education and training (VET) in the European Union may offer some evidence for this issue.

\section{Flexibility reconsidered}

Nijhof, Heikkinen, and Nieuwenhuis (2002) described the results of Working Group 4 of the Cost Project, in which researchers of 16 countries were involved in the study of shaping conditions for a flexible VET system. They considered flexibility as 'the core concept of economic and educational change in our time' (p. 3). Current economic 
demands urge important transitions in education: from initial to lifelong learning, from traditional occupations to qualifications or competences, from school learning to work experience, from social demands to market-economy demands, from employee to employer roles. Students need sustainable competences and skills to be equipped for transferability, mobility and employability in lifelong learning and working. VET systems need 'systemic flexibility' to prepare students for the future, which requires '...an enormous curricular and throughput flexibility or adaptability at all levels in the different VET systems' (Nijhof et al., 2002, p. 4). Authors of the national studies come up with several interesting developments, which support the need for a flexible educational model.

Mayer (2002) considers the 'learning-economy' paradigm as a major shift in economy. He argues that flexibility gets a new connotation in the emerging social organisation of innovation. Employees need flexibility in terms of trainability and learning skills, and must have access to codified- as well as tacit-knowledge bases. Therefore, in education, planned and predictable learning must be replaced by constructivist and experience-based learning, flexible and just in time.

Nieuwenhuis (2002) considers 'networking' as a keyword in a learning economy, in which working teams and social networks play an important role in sharing knowledge as part of informal learning processes. Learning and working inside colleges must be reorganised in order to interact with the regional economy. Colleges need flexibility in order to bridge the inconsistencies of the worlds of working and learning. Nieuwenhuis concludes that a redesign of the fundamental processes and culture in education is required: '... without a systemic debate and a paradigm shift at all levels in the educational system, the margins for innovative policies at college level will remain restricted' (Nieuwenhuis, 2002, p. 49). These and other studies in VET (Nijhof et al., 2002) generally support the idea that flexibility is a basic concept for a new learning approach that transcends operational flexibility.

\section{Expert validation}

In order to direct further research and development, educational experts were asked to answer the question: 'Does the flexible educational model offer a valid representation for HPE institutes in The Netherlands and can it contribute to increasing the operational flexibility of educational programmes and improving the conditions for innovation?' According to Law and Kelton (2000), a simulation model is valid if it is clearly accepted as 'credible' for its purpose. The experts validated the simulated model on a range of operational characteristics. The research approach and the contribution of the model to flexibility and to innovation were evaluated by means of a questionnaire and a guided group discussion, in which theoretical issues and practical problems were explored.

\section{Method}

\section{Participants}

Four experts were involved in this validation study: an emeritus professor in education with extensive international experience, a university professor in education, a HPE lecturer in affairs of students accessing higher education, and a senior research staff member at a support institute for the innovation of professional education. Together 
these experts represented more than a century of national and international work experience in the field of higher education and educational policy in The Netherlands.

\section{Materials}

The materials for this study consisted of a detailed description of a representative HPE institute, an article on operational flexibility, a set of specimen for demonstration of the model simulation, an extensive questionnaire, a checklist of topics for a group discussion, and several PowerPoint presentations.

The description of the HPE institute was produced for the case study (Schellekens et al., 2009). The article on operational flexibility represented the approach and results of a survey (Schellekens et al., 2003), which were utilised to produce the questionnaire.

The simulation model covered 26 characteristics representing the educational system of the case institute, such as the curriculum, programmes, student population, grouping, planning and assessment. The specimen for demonstration of the model mainly consisted of simulation input and output data, regarding, among others, intake of students, programme activities, study results, staff group capacities, outflow of certified and dropped-out students.

The questionnaire had sections for the research approach, validation of the simulated model, flexibility of the model, and evaluation of the model. Each section contained questions on related topics. Each question consisted of statements regarding section-relevant aspects (see Table 1 for an overview).

The checklist for the group discussion addressed a set of general questions on the possible contribution of the model for increasing the flexibility of education, its feasibility and desirability, underlying concepts and principles, theoretical and practical implications, and consequences for future development and research. In addition, a set of specific topics regarded implications of the model for educational legislation, financial exploitation, interests of stakeholders involved, national and European educational policies, actual developments in educational innovation, and possible consequences for the function and position of HPE institutes in society.

Additional presentations were used for a general introduction, to present the flexible educational model, and to introduce the questionnaire.

\section{Procedure}

The experts were invited for a five-hour meeting. In advance, they received the case institute description and the article on operational flexibility (Schellekens et al., 2003). The meeting started with a plenary presentation of the flexible educational model ( 60 minutes) and a demonstration using the specimen of the simulation run (30 minutes). Next, the experts had the opportunity to get additional information (60 minutes). After a one-hour lunch break the questionnaire was introduced with a plenary presentation (15 minutes) and individually filled in by the experts (60 minutes). The meeting was completed with a plenary discussion (75 minutes) using the checklist. This discussion was chaired by a fifth educational expert (experienced university professor in educational technology) and taped on video in order to produce a verbatim account of the discussion. It was decided that for a positive answer to the research question the mean expert scores for each section of the questionnaire had not to be negative (i.e., positive or at least neutral). 


\section{Results}

\section{Questionnaire}

All questions consisted of statements to be scored on a five-point scale ( -2 , 'disagree' to +2 , 'agree'). Mean scores per expert were determined for the aspects included in the questions of each section. These mean expert scores $(n=4)$ were compared with a negative score of -1 (i.e. all experts scoring a mean of -1 ) using a one-sample twotailed $t$-test at $95 \%$ and $99 \%$ confidence levels. The results are presented in Table 1.

The research approach was scored on four topics: problem definition; definition of flexibility; research structure; and research question. The mean scores per expert for clearness of the research approach were significant at $99 \%$ confidence level. Acceptance of the research approach scored significant at the 95\% level.

The validity of the flexible educational model was scored on 26 operational characteristics and for the model in general. The mean expert scores for clearness were significant at the $99 \%$ level. Acceptance of the validity of the model scored significantly at the $95 \%$ level. These results were confirmed by an additional question on the validity of the model as a whole. Clearness scored significantly at the $99 \%$ level $(M=$ $\left.1.25, S D=0.500 ; t_{(4)}=9, p=0.003\right)$. Validity scored significantly at the $95 \%$ level $\left(M=0.75, S D=0.957 ; t_{(4)}=3.656, p=0.035\right)$.

The flexibility of the model was scored on operational characteristics in the categories: environment (seven questions); curriculum (seven questions); activities (nine questions); facilities (nine questions), as described in Schellekens et al., (2009); and in general (one). The flexibility of the model scored significantly at the $99 \%$ confidence level. Realisation of flexibility in the model and innovativity of the model scored significantly at the $95 \%$ level. The significant result for innovativity was not confirmed by the expert scores of the general question $\left(M=0.50, S D=1.29 ; t_{(4)}=2.324, p=0.103\right)$.

Table 1. Expert judgements on questionnaire topics.

\begin{tabular}{lcccc}
\hline Topics $(n)$ & $M$ & $S D$ & $t(\mathrm{df}=4)$ & $p$ \\
\hline Research design (4) & & & & \\
Clearness & 0.75 & 0.35 & 9.899 & $0.002^{* *}$ \\
Acceptance & 0.81 & 0.77 & 4.684 & $0.018^{*}$ \\
Model validity (26) & & & 7.871 & $0.004^{* *}$ \\
Clearness & 0.94 & 0.49 & 4.411 & $0.022^{*}$ \\
Acceptance & 0.75 & 0.79 & & \\
Model flexibility (32) & & & 5.091 & $0.015^{*}$ \\
Realisation & 0.79 & 0.71 & 7.571 & $0.005^{* *}$ \\
Flexibility & 1.14 & 0.57 & 5.035 & $0.015^{*}$ \\
Innovation & 0.77 & 0.7 & & \\
Model evaluation (2) & & & 2.183 & 0.117 \\
Feasible & 0.13 & 1.03 & 4.041 & $0.027^{*}$ \\
Useful & 0.75 & 0.87 & 12.124 & $0.001^{* *}$ \\
Desirable & 0.75 & 0.29 & 7.833 & $0.004^{* *}$ \\
Innovative & 0.88 & 0.48 & & \\
\hline
\end{tabular}

Note: Participants were four experts who answered $n$ questions on aspects of each topic; judgements were made on five-point scales ( -2 , disagree to +2 , agree); the probability $(p)$ of the mean scores $(M)$ was compared with a negative score of -1 by means of a two-tailed $t$-test; ${ }^{*} p<0.05 ;{ }^{*} p<0.01 ; S D$, standard deviation. 
The significant results for realisation $\left(M=0.75, S D=0.50 ; t_{(4)}=7.00, p=0.006\right)$ and flexibility $\left(M=1.50, S D=0.58 ; t_{(4)}=8.66, p=0.003\right)$ were confirmed.

The evaluation of the model concerned the practicability of the model for the case institute (local), and for other HPE institutes in The Netherlands (national). For each topic four aspects were scored: feasibility (the model can be realised in practice); usefulness (applying has a positive effect on flexibility); desirability (applying is recommended); and innovativity (conditions for innovation are improved). Feasibility scored not significantly positive. Further analysis showed that this negative result could be ascribed fully to the local condition $\left(M=0.00, S D=1.633 ; t_{(4)}=1.225\right.$, $p=0.308)$, with the national condition $\left(M=0.25, S D=0.58 ; t_{(4)}=5.00, p=0.015\right)$ scoring significantly positively at the $95 \%$ level. Usefulness (at the $95 \%$ level), desirability and innovativity (both at the $99 \%$ level) scored significantly positively. The overall mean scores of the experts were, respectively: $M=1.65, S D=0.629 ; M=0.99$, $S D=0.939 ; M=0.43, S D=0.745 ;$ and $M=0.41, S D=0.727$.

With the exception of the local scores for feasibility and the in-general scores on the innovativity aspect of flexibility, all mean expert scores were significantly positive.

\section{Group discussion}

Important issues in the group discussion were the validity and usability of the model, the roles of teachers, students and management concerning the implementation of the model, and recommendations for further research and development.

The validity of the model in terms of 'face validity', 'construct' or 'concept' validity, and its usability in terms of 'relevance for practice' were considered as positive by all the experts. They agreed that the 26 operational characteristics covered all the necessary aspects for a valid model. In the model, two components were clearly distinguished: a simulation tool; and a curriculum approach. The simulation tool was appreciated as a general tool for offering insight in operational processes in education. For the competence-based curriculum approach, output differentiation was considered a necessary feature of the model.

For the practical application of the model, the risk of implementation failure was considered high, with an obvious need to prepare teachers and students for a flexible approach in order to develop new routines. Other critical issues mentioned were: costs and other financial aspects; content flexibility; portfolio functionality; and administrative support. Special attention was requested for the implementation of projects, cooperation of students at different expertise levels, and the introduction of new teacher roles. It was expected that managers would welcome the increased operational flexibility to solve urgent organisational problems.

For further research the experts suggested to apply the model for creating awareness on the flexibility issue in a larger number of HPE institutes. The simulation could be used as a tool for analysing the available curriculum and for experimentation with possible solutions for increasing the flexibility of educational programmes. For further development it was recommended to prove the existential value of the model by modest steps in implementing the approach on a small scale with realistic goals.

\section{Conclusion}

From the questionnaire results it can be concluded that the flexible educational model offers a valid representation of HPE institutes in The Netherlands, and that it has the 
potential to contribute to increasing the operational flexibility of educational programmes and improving the conditions for innovation. A restriction must be made for the judgements on the feasibility of the model in the local situation. The innovativity aspect concerning the flexibility of the model was ammended.

\section{Discussion}

Although the number of experts was relatively small, the research question can be considered confirmed by the questionnaire results. The research approach and the model were clear, and the validity of the model was accepted by the experts. The group discussion results are consistent with the questionnaire results and also throw more light on the restrictions that must be made.

The low scores on feasibility may indicate the fear of implementation failure expressed in the group discussion, which can severely threaten the application of a flexible model in a local situation. The low general score on the innovativity aspect of flexibility may reflect the circumstance that the implementation of the model in the simulation did not make full use of the innovative educational opportunities enabled by the flexible model. In order to validate the flexible model, important operational characteristics as programmes and intake patterns were taken as given in the caseinstitute situation.

In the research approach the simulation model has played an important role in developing and testing new operational structures and processes. For further studies, this simulation model needs refinement. Simulations could be more realistic by introducing a real calendar and clock structure, instead of time units, thus including, for instance, weekends in which students can plan their study activities. More realistic planning procedures are needed to match demand and supply of courses with a scope of more than just one week ahead. A system of competences and competence levels is needed in order to assign tasks to students in real projects or work. A next version of the simulation must not only take into account teaching staff capacities, but also the operational constraints of accommodation and facilities.

From a theoretical point of view it is important that the application of a flexible educational model in a regular HPE institution, as demonstrated in the simulation, is accepted by the experts. A substantial increase of flexibility in existing HPE institutions meets the need for customised education and training in the perspective of lifelong learning (Markkula et al., 2000). Application of the flexible model may offer the 'systemic flexibility' that is needed for important transitions in education (Nijhof et al., 2002). Freeing education from the strongly enclosing operational format of the common model can bridge the worlds of working and learning in order to involve students in wider local networking (Nieuwenhuis, 2002) and to give them access to tacit knowledge in a more natural way (Mayer, 2002).

But before these and other wishful developments can take effect, many practical issues require further theoretical elaboration and research. An interesting line of research concerns the development of assessment procedures in such a way that they can support the flexible operational solutions of the model. Another idea of the experts was to define the operational dimensions that are influenced by different educational approaches in order to develop profiles for describing educational arrangements.

In practice, increasing the flexibility of educational programmes is just one solution for educational innovation. Many critical issues must be considered to change a well-balanced and persistent educational system which has evolved in many decades 
as a proven way to educate HPE students. The interests of diverse stakeholders in education, students and teachers, departments of education, and future employers must be considered. A new educational format must be embedded in the social and societal context of education. Consequences of changing aims and services of educational institutes must be considered from local, national and international perspectives, taking into account legal and financial conditions. However, taking all these and many other aspects into account, the results of this study may contribute to building evidence that replacing the well-trusted, centrally scheduled planning in educational institutes with more flexible operational structures and processes is a crucial aspect for innovation in HPE.

\section{Notes on contributors}

Ad Schellekens completed a career in the field of educational technology with a $\mathrm{PhD}$ on operational flexibility in higher professional education at the Open Universiteit Nederland. Since 1974, after a teacher training and postgraduate educational technology programme, he managed projects in educational innovation and technology for the national educational support institutions (LPC), Royal Philips Electronics Inc., and Open Universiteit Nederland. His interests focus on the design and development of innovative educational systems.

Fred Paas is a full professor of educational psychology at the Institute of Psychology of Erasmus University Rotterdam in The Netherlands. His research interests include the instructional control of cognitive load in the training of complex cognitive tasks.

Alexander Verbraeck is a full professor in systems and simulation, and chair of the Systems Engineering Department of the Faculty of Technology, Policy and Management of Delft University of Technology. In addition, he is part-time research professor in supply chain management at the R.H. Smith School of Business of the University of Maryland. His research focuses on discrete-event simulation, serious gaming, and project management.

Jeroen J.G. van Merriënboer is full professor of learning and instruction in the Department of Educational Development and Research and programme director of the School of Health Professions Education at Maastricht University. His research interests include instructional design for complex learning and ICT-based learning environments. Most of his work is related to four-component instructional design and cognitive load theory.

\section{References}

Krajewski, L.J., \& Ritzman, L.P. (1996). Operations management: Strategy and analysis (4th ed.). Reading, MA: Addison-Wesley Publishing Company.

Law, A.M., \& Kelton, W.D. (2000). Simulation modeling and analysis (3rd ed.). Boston, MA: McGraw-Hill.

Markkula, M., Van der Perre, G., \& Claeys, C. (2000). Why would universities be in place to offer learning on demand? In A. Rocha-Trindade (Ed.), New learning. Plenary review papers of the Lisbon 2000 European conference: 'ODL Networking for Quality Learning' (pp. 327-339). Lisbon, Portugal: Universidade Aberta.

Mayer, K. (2002). Vocational education and training in transition: From Fordism to a learning economy. In W.J. Nijhof, A. Heikkinen, \& L.F.M. Nieuwenhuis (Eds.), Shaping flexibility in vocational education and training (pp. 17-33). Dordrecht, The Netherlands: Kluwer Academic Publishers.

Nieuwenhuis, L.F.M. (2002). Learning organisations for VET. In W.J. Nijhof, A. Heikkinen, \& L.F.M. Nieuwenhuis (Eds.), Shaping flexibility in vocational education and training (pp. 35-52). Dordrecht, The Netherlands: Kluwer Academic Publishers.

Nijhof, W.J., Heikkinen, A., \& Nieuwenhuis, L.F.M. (Eds.). (2002). Shaping flexibility in vocational education and training. Dordrecht, The Netherlands: Kluwer Academic Publishers. 
Schellekens, A., Paas, F., \& Van Merriënboer, J.J.G. (2003). Flexibility in higher professional education: A survey in business administration programmes in The Netherlands. Higher Education, 45, 281-305.

Schellekens, A., Paas, F., Verbraeck, A., \& Van Merriënboer, J.J.G. (2009). Designing a flexible approach for higher professional education by means of simulation modelling. Journal of the Operational Research Society, 61, 202-210.

Van Merriënboer, J.J.G. (1997). Training complex cognitive skills: A four-component instructional-design model for technical training. Englewood Cliffs, NJ: Educational Technology Publications. 